Research Article

\title{
Effect of Roughness on Shear Characteristics of the Interface between Silty Clay and Concrete
}

\author{
Yonghong Wang $\mathbb{D}^{1,2}$ Xueying Liu, ${ }^{1}$ Mingyi Zhang $\mathbb{D}^{1,2}$ and Xiaoyu Bai ${ }^{1,2}$ \\ ${ }^{1}$ School of Civil Engineering, Qingdao University of Technology, Qingdao 266033, China \\ ${ }^{2}$ Cooperative Innovation Center of Engineering Construction and Safety in Shandong Blue Economic Zone, \\ Qingdao University of Technology, Qingdao 266033, China
}

Correspondence should be addressed to Mingyi Zhang; zhangmingyi@qut.edu.cn

Received 20 July 2020; Revised 17 September 2020; Accepted 5 October 2020; Published 20 October 2020

Academic Editor: Liborio Cavaleri

Copyright (C) 2020 Yonghong Wang et al. This is an open access article distributed under the Creative Commons Attribution License, which permits unrestricted use, distribution, and reproduction in any medium, provided the original work is properly cited.

\begin{abstract}
In order to study the effect of roughness on the mechanical parameters of silty clay-concrete interface, and to explore the applicability of silicon piezoresistive sensor to test the interface pressure, a large-scale direct shear test system was used to carry out experimental research on the shear characteristics of silty clay-concrete interface under different roughness conditions. Based on silicon piezoresistive sensor, the shear characteristics of silty clay-concrete interface are analyzed. The results show that the silicon piezoresistive sensor has excellent performance in measuring the interface pressure and can accurately obtain the shear characteristics of the silty clay-concrete interface. The roughness has a significant influence on the shear strength, shear stiffness, and other mechanical properties of the prefabricated pile-soil interface. With the increase of roughness, interface shear strength, interface friction angle, shear stiffness coefficient, and interface residual shear stress all show an increasing trend, with the maximum increase of $37.0 \%$. The interface adhesion decreased first and then increased with the increase of roughness, with an increase of $23.7 \%$. The test results can provide reference for the engineering practice of jacked pile.
\end{abstract}

\section{Introduction}

In recent years, with the continuous and in-depth research on jacked pile technology, many scholars at home and abroad have begun to conduct in-depth research on the problems existing in the pile-soil interface, and the stress characteristics of the pile-soil interface have become the mainstream of research [1-3]. At present, studies on the mechanical characteristics of pile-soil interface mainly focus on the acquisition and separation of shear strength indexes under load to analyze the relationship between shear strength and normal stress, friction coefficient and soil strength, and the interface friction coefficient and the roughness of contact surface [4].

At present, the research methods of shear characteristics of pile-soil interface mainly include laboratory test $[5,6]$, theoretical study $[7,8]$, and field test $[9,10]$. Indoor direct shear test has gradually become the main research method due to its advantages of controllable variables, low cost, and easy operation. The direct shear test simulates different working conditions by changing soil types and external stress conditions to obtain the relevant parameters of shear characteristics and reveal the influencing factors and change rules in the pile-soil interaction process. Zhang and Deng [11] conducted an indoor model shear test with an improved direct shear apparatus and studied the timeliness of sliding friction resistance at the prefabricated pile-clay interface. It is found that the time efficiency is significant and the curve type increases with the increase of time. The test results lay a foundation for the numerical simulation of jacked pile and the research on the bearing capacity of foundation pile. Cheng et al. [12] studied the law of residual strength affected by roughness through the red clay-concrete interface shear test and concluded that the increase of roughness can improve the residual shear strength, and the normal stress also affects the size of residual strength. Hu et al. [13] analyzed 
and explained the sliding friction mechanism of the static pressure pile-soil interface based on the theory of adhesive friction mechanism and deformation friction mechanism, which provided a new idea for studying jacked piles. Yang et al. [14] studied the mechanical mechanism of different soil samples and concrete at the contact interface through the indoor ring shear simulation test. It is found that there is a significant linear relationship between the shear stress and the normal stress at the interface shear failure, and the change law of the interface shear strength has a higher applicability to the Mohr-Coulomb criterion. Peng et al. [15] conducted the interface shear test between bentonite and mixed soil (bentonite and cement) and concrete in a large single shear apparatus. It is found that the shear strength and shear displacement curve have obvious softening segment, and the shear stress peak position is related to the normal stress and the cement content in the mixed soil. Liu et al. [16] conducted shear tests on soil-PHC pipe pile interface based on the pile-soil interface shear instrument, conducted an indepth study on the problem of shear fatigue degradation, and analyzed the variation law of shear degradation amplitude and shear cycle number. Zhou et al. [17] conducted the shear characteristics test of slate sandy soil-concrete interface under different water content based on the largescale direct shear test system. It is found that water content has a significant influence on the shear strength, shear stiffness, and shear failure deformation of the slaty-concrete interface. Xu and Meng [18] studied the influences of shear rate and reinforced material characteristics on the interface strength of reinforced soil on the basis of the geogrid-sand direct shear test. Song et al. [19] conducted experimental research on the shear characteristics of sliding-zone soils with different moisture content based on large indoor direct shear apparatus. The shear characteristics are studied, and the shear stress-strain relationship is characterized by weak strain hardening, and the greater the normal stress is, the more obvious it is. In the existing direct shear tests, the influence factors of shear strength have been studied effectively and some beneficial results have been obtained.

Therefore, in order to further solve practical engineering problems, the influences of roughness, water content, and shear rate on soil-structure interface shear stiffness and failure deformation should also be studied in addition to shear strength, which is rarely studied at present. In this paper, through the direct shear model test of the pile-soil interface, the variation of shear stress and displacement at different friction stages during the interface shearing process are analyzed by factors such as interface roughness and effective normal stress. Based on the Mohr-Coulomb friction theory, a linear fitting method is used to separate the friction and adhesion at the sliding friction stage, and the effect of the above different conditions on the friction angle and adhesion at the pile-soil interface is further explored. The effect of roughness on shear failure displacement and interfacial shear stiffness was studied, and the mechanism of the influence of the above factors on the shear properties of silty clay-concrete interface was explained at a meso level.

\section{Development of Miniature Silicon Piezoresistive Sensor}

2.1. Piezoresistive Effect of Polysilicon Materials. The phenomenon that the resistance of polysilicon material changes under the action of external force is called piezoresistive effect. According to resistance $R=\rho L / A$, differentiation [20] can be obtained as follows:

$$
\frac{\mathrm{d} R}{R}=\frac{\mathrm{d} \rho}{\rho}+\frac{\mathrm{d} L}{L}-\frac{\mathrm{d} A}{A}=\frac{\mathrm{d} \rho}{\rho}+(1+2 v) \varepsilon,
$$

where $R$ is the resistance of polysilicon material; $\rho$ is the resistivity of polysilicon material; $L$ is the length of polysilicon material; $A$ is the cross-sectional area of polycrystalline silicon material; $v$ is the Poisson coefficient of polysilicon; and $\varepsilon$ is the strain of polysilicon material.

Stress causes a change in the resistivity of the polysilicon material. According to the relative changes of stress and resistivity and the relationship between stress and strain,

$$
\begin{gathered}
\frac{\mathrm{d} \rho}{\rho}=\pi \sigma, \\
\sigma=E \varepsilon .
\end{gathered}
$$

From equations (1) to (3), it can be obtained that

$$
\frac{\mathrm{d} R}{R}=\frac{\mathrm{d} \rho}{\rho}+(1+2 v) \varepsilon=(1+2 v+\pi E) \varepsilon=G F \mathcal{\varepsilon},
$$

where $G F=1+2 v+\pi \mathrm{E}$ is the strain coefficient.

According to equation (4), the strain coefficient of polysilicon material is related to $1+2 v$ and $\pi E$. The geometrical deformation caused by polysilicon material under stress is far less than the resistivity change caused by it, and its piezoresistivity coefficient is large, $1+2 v$ can be ignored, and $G F=72.4 \sim 149.6$. The piezoresistive effect of metal materials is mainly caused by the change of material geometry size, and its piezoresistive coefficient can be considered as $0, G F=1.5 \sim 2.0$; that is, polysilicon materials have a higher sensitivity coefficient than metal materials.

2.2. Working Principle of Silicon Piezoresistive Earth Pressure Sensor. Silicon piezoresistive Earth pressure sensor adopts the advanced miniaturization process and integrates silicon pressure diaphragm as the sensing element. By utilizing the piezoresistive effect of polysilicon, four polysilicon pressuresensitive resistors are prepared by deposition of silicon dioxide on the insulating layer deposited on the pressure diaphragm, forming Wheatstone bridge [21, 22]. Schematic diagram of silicon piezoresistive pressure sensor is shown in Figure 1, and Wheatstone bridge circuit is shown in Figure 2.

In this paper, Wheatstone bridge adopts the power supply mode of constant voltage source. The pressure difference on both sides of the silicon diaphragm changes the resistance values of the four resistors above. Wheatstone bridge is out of balance, and the output voltage [23] is 


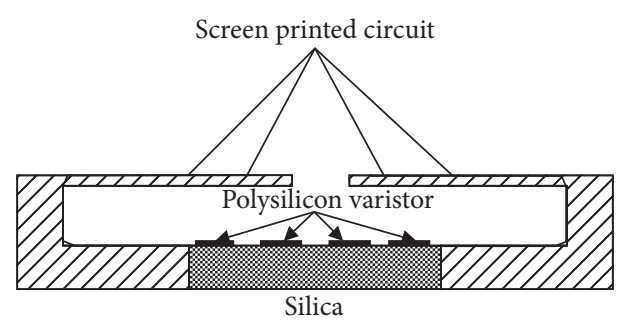

Figure 1: Schematic diagram of silicon piezoresistive pressure sensor.

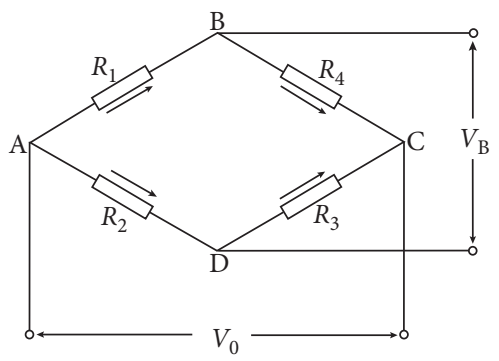

FIGURE 2: Wheatstone bridge circuit.

$V_{0}=\frac{\left[\left(R_{1}+\Delta R_{1}\right)\left(R_{3}+\Delta R_{3}\right)-\left(R_{2}-\Delta R_{2}\right)\left(R_{4}-\Delta R_{4}\right)\right]}{\left(R_{1}+R_{2}+\Delta R_{1}-\Delta R_{2}\right)\left(R_{3}+R_{4}+\Delta R_{3}-\Delta R_{4}\right)} \times V_{\mathrm{B}}$

where $V_{\mathrm{B}}$ is the supply voltage and $V_{0}$ is the output voltage. $R_{1}=R_{3}=R_{2}=R_{4}=R$; then, $\Delta R_{i}=R \cdot G F \cdot \varepsilon_{i}(i=1,2,3,4)$; $\varepsilon_{i}$ is the strain value of the $i$-th resistance, and we get the following:

$$
V_{0}=\frac{1}{4} G F \cdot \frac{\varepsilon_{1}+\varepsilon_{3}-\varepsilon_{2}-\varepsilon_{4}}{\left[1+(1 / 2)\left(\varepsilon_{1}+\varepsilon_{2}+\varepsilon_{3}+\varepsilon_{4}\right)\right]} V_{\mathrm{B}} .
$$

When the sensor is designed, make the four resistance strain values meet $\varepsilon_{1}=\varepsilon_{3}=-\varepsilon_{2}=-\varepsilon_{4}=\varepsilon$; equation (6) becomes

$$
V_{0}=G F \cdot \varepsilon \cdot V_{\mathrm{B}}
$$

By equation (7), it can be seen that the relationship between Wheatstone bridge voltage and the strain value on the pressure-sensitive resistance is linear. Output voltage can be realized under the action of outside pressure measurement, and the voltage value is also associated with diaphragm strain coefficient; the greater the strain coefficient and strain value, the greater the bridge output pressure value, and the higher the sensor sensitivity.

2.3. Design of Silicon Piezoresistive Earth Pressure Sensor. The miniature silicon piezoresistive pressure sensor adopts the advanced miniaturization manufacturing process to integrate silicon diaphragm as the sensing element. The four resistors on the diaphragm are connected by screen printing lines, and the metal shell is used for delicate micro-encapsulation [24, 25]. The schematic diagram of sensor packaging structure is shown in Figure 3, and the photo of sensor is shown in Figure 4.

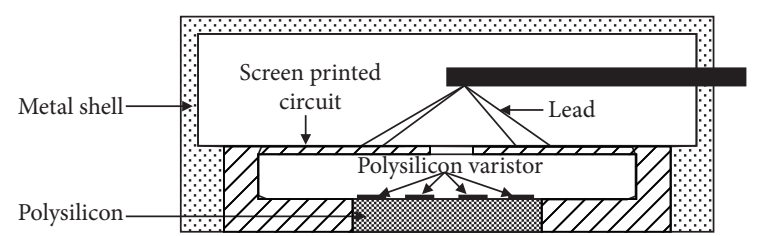

FIgURE 3: Packaging schematic diagram of miniature silicon piezoresistive Earth pressure sensor.

According to the test requirements, silicon piezoresistive soil pressure sensor and silicon piezoresistive pore water pressure sensor are adopted, and the surface of pore water pressure sensor is sealed with pervious stone.

The calibration test results show that the silicon piezoresistive pressure sensors have good linear fitting degree, and the linear correlation coefficient is above 0.99 . The specific performance indexes of the miniature silicon piezoresistive pressure sensors are shown in Table 1.

2.4. Sensor Calibration Test and Result Analysis. The silicon piezoresistive pressure sensor was tested, and the operating characteristic curve of the sensor under each pressure test point of upper and lower travel is shown in Figure 5.

Silicon piezoresistive pressure sensor is made by using polycrystalline silicon as elastomer and silicon diaphragm as sensing element in advanced miniaturization process, which ensures the normal stiffness of the sensor. The silicon piezoresistive pressure sensor has high dynamic frequency response and adopts the power supply mode of constant current source with reduced zero drift and simple circuit to eliminate the influence of temperature on the bridge output.

\section{Interfacial Shear Test}

3.1. Test Equipment. The direct shear test instrument was a pile-soil interface shear instrument made by Qingdao University of Technology [26]. Both the upper and lower shear boxes were rectangular in shape, and the shear bottom box was $40 \mathrm{~cm} \times 27 \mathrm{~cm} \times 20 \mathrm{~cm}$ (length $\times$ width $\times$ height), which can be used to conduct direct shear tests on various contact interfaces of the Earth.

3.2. Test Design. The test was divided into 4 groups, with 4 samples in each group. During the test, 4 grades of normal stress were applied to each sample, respectively, $25 \mathrm{kPa}$, $50 \mathrm{kPa}, 100 \mathrm{kPa}$, and $150 \mathrm{kPa}$, and the shear rate was set at $1.0 \mathrm{~mm} / \mathrm{min}$. According to the Standards for Geotechnical Test Methods [27], the test soil samples were uniformly configured with a medium compressible remolded silty clay with a moisture content of $25 \%$. The physical indexes of soil samples are shown in Table 2. The test preparation process is shown in Figure 6.

The large direct shear test was used to study the shear strength characteristics of the silty clay-concrete interface. The lower shear box shall be replaced by a concrete block. In accordance with the relevant requirements of "Technical code for building pile foundations" [28], C50 concrete was used 


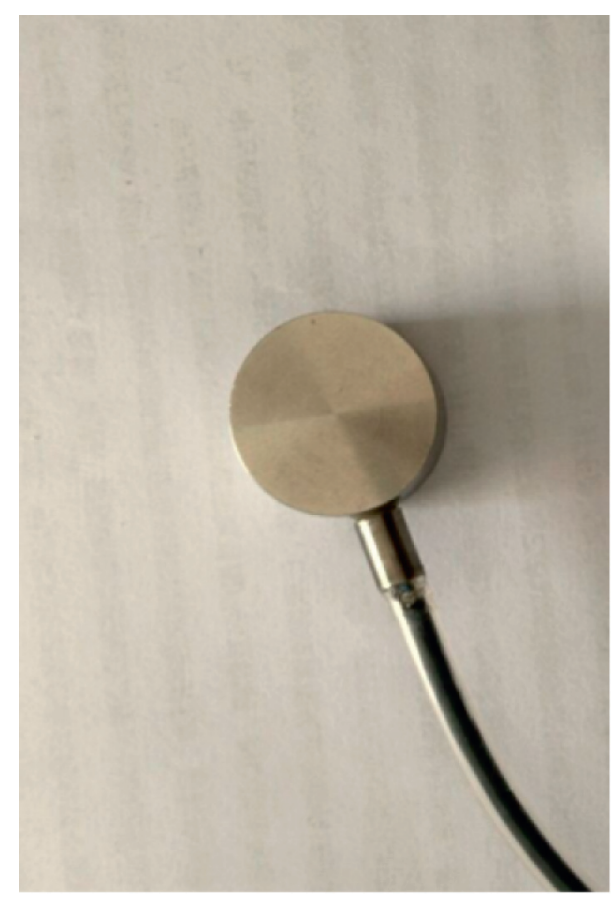

Figure 4: Photo of miniature silicon piezoresistive Earth pressure sensor.

TABle. 1: Performance indexes of miniature silicon piezoresistive pressure sensor.

\begin{tabular}{lc}
\hline Parameter & Earth pressure transducer \\
\hline Range $(\mathrm{kPa})$ & 500 \\
Dynamic frequency response $(\mathrm{kHz})$ & 2000 \\
Accuracy & $0.1 \%$ \\
Interface method & Self-locking structure \\
Appearance of size $(\mathrm{mm} \times \mathrm{mm})$ & $20 \times 10$ \\
\hline
\end{tabular}

for the concrete blocks. In actual engineering, soil and reinforced concrete structure of contact interface is usually a rough surface. The different roughness settings in this experiment showed different interface shear mechanical properties, so the tooth grooves with $R$ (peak-valley distance) of $0,2,4$, and $6 \mathrm{~mm}$ were set in this experiment to simulate different roughness states of pile-soil interface (with the top of the tooth groove $2 \mathrm{~mm}$ wide, lower $10 \mathrm{~mm}$ wide), as shown in Figure 7 . According to the studies by D'Andrea et al. [29] and Hayashi et al. [30], the roughness setting of this test can better simulate the shear mechanical characteristics of pile-soil interface. The interfacial shear stress was measured by a high precision tension sensor mounted on the rotating screw of the shear instrument. The dynamic data acquisition system adopted in the test includes a computer, data demodulator, and instantaneous display. The test device is shown in Figure 8.

3.3. Sensors and Test System. Silicon piezoresistive pore water pressure sensor's diameter $\times$ height is $8 \mathrm{~mm} \times 15 \mathrm{~mm}$, and silicon piezoresistive earth pressure sensor's diameter $\times$ height is $20 \mathrm{~mm} \times 10 \mathrm{~mm}$. The data acquisition system of silicon piezoresistive sensor adopts dynamic data acquisition system, which is composed of data acquisition module and supporting virtual instrument software. The conductor of silicon piezoresistive sensor is connected with the acquisition equipment of USB7660/2. Data acquisition is conducted through supporting virtual instrument software of EM9636B to monitor effective normal stress in real time.

\section{Roughness Affects Test Results and Analysis}

\subsection{Influence of Roughness on Interface Shear Strength}

4.1.1. Interface Shear Strength. According to the test results, the shear strength variation curve of pile-soil interface with different roughness can be drawn, as shown in Figure 9. It can be seen that when normal stress was the same, the shear strength increased with the increase of roughness. When normal stress $\sigma=150 \mathrm{kPa}$, the interface shear strength increased from $69.43 \mathrm{kPa}$ to $94.31 \mathrm{kPa}$ with the increase of roughness from $0 \mathrm{~mm}$ to $4 \mathrm{~mm}$, with an increase of $35.8 \%$. This indicated that the roughness had a significant influence on the shear strength of the silty clay-concrete interface.

4.1.2. Interface Friction Angle and Interface Adhesion. The relationship between shear strength and roughness is shown in Figure 10. It can be seen that when the roughness was the same, the relationship between shear strength and normal stress can be approximately considered as a linear increase, satisfying the Mohr-Coulomb criteria. The ultimate frictional resistance at the silty clay-concrete interface was similar to the shear strength of soil, and Mohr-Coulomb criteria is expressed as

$$
q_{\mathrm{u}}=\sigma \cdot \tan \phi_{\mathrm{a}}+c_{\mathrm{a}},
$$

where $q_{\mathrm{u}}$ is the ultimate friction resistance at the pile-soil interface; $\sigma$ is the normal stress at the interface; $\varphi_{\mathrm{a}}$ is the friction angle at the pile-soil interface; and $c_{\mathrm{a}}$ is the adhesion force of the pile-soil interface.

$c_{\mathrm{a}}$ and $\varphi_{\mathrm{a}}$ can be obtained by fitting the data according to the Mohr-Coulomb criteria. The fitting correlation coefficient of the fitting function obtained from Figure 10 was $0.9781 \sim 0.9943$, and the fitting effect was good, and the relation curve between $c_{\mathrm{a}}$ and $\varphi_{\mathrm{a}}$ and roughness can be obtained, as shown in Figures 11 and 12.

As can be seen from Figure 11, with the increase of roughness, the interface adhesion decreased from $17.87 \mathrm{kPa}$ to $13.81 \mathrm{kPa}$ and then increased to $20.63 \mathrm{kPa}$, reaching a maximum of $22.11 \mathrm{kPa}$. The final increase value was $4.24 \mathrm{kPa}$, with an increase of $23.7 \%$. As can be seen from Figure 12, with the increase of roughness, the interface friction angle gradually increased from $19.29^{\circ}$ to $24.23^{\circ}$, and finally to $25.17^{\circ}$. The final increase value was $5.88^{\circ}$, and the increase range was $30.5 \%$. Overall, roughness for interface adhesion and interface friction angle had great. At the same time, compared with the soil physical and mechanical parameters, it can be seen that the interface adhesion and the interface friction angle are less than the data of soil. Its value was relatively close; the shear characteristics of the interface were related to the properties of soil. 


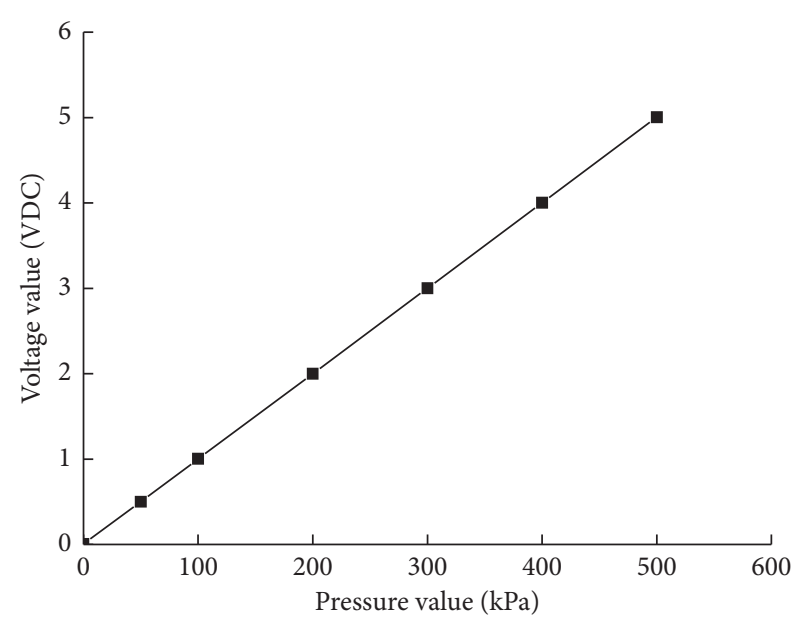

(a)

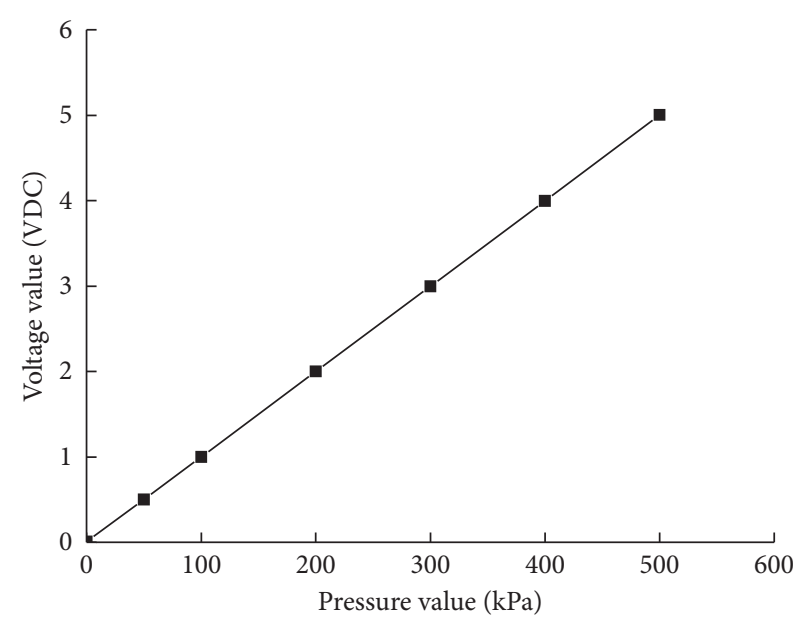

(b)

FIgURE 5: Work curves of silicon piezoresistive soil pressure sensor under different pressures. (a) Up stroke. (b) Down stroke.

TABLE 2: Soil physical properties indicators.

\begin{tabular}{lcccccccccc}
\hline $\begin{array}{l}\text { Density } \\
\left(\mathrm{g} / \mathrm{cm}^{3}\right)\end{array}$ & $\begin{array}{c}\text { Dry } \\
\text { density } \\
\left(\mathrm{g} / \mathrm{cm}^{3}\right)\end{array}$ & $\begin{array}{c}\text { Relative } \\
\text { density }\end{array}$ & $\begin{array}{c}\text { Liquid } \\
\text { limit } \\
(\%)\end{array}$ & $\begin{array}{c}\text { Plastic } \\
\text { limit } \\
(\%)\end{array}$ & $\begin{array}{c}\text { Internal } \\
\text { friction } \\
\text { angle }\left(^{\circ}\right)\end{array}$ & $\begin{array}{c}\text { Cohesion } \\
(\mathrm{kPa})\end{array}$ & $\begin{array}{c}\text { Saturability } \\
(\%)\end{array}$ & $\begin{array}{c}\text { Void } \\
\text { ratio }\end{array}$ & $\begin{array}{c}\text { Compression } \\
\text { coefficient } \\
\left.(\mathrm{MPa})^{-1}\right)\end{array}$ & $\begin{array}{c}\text { Compression } \\
\text { modulus }(\mathrm{MPa})\end{array}$ \\
\hline 1.98 & 1.58 & 2.73 & 31.3 & 16.5 & 30 & 27 & 94.9 & 0.728 & 0.32 & 5.5 \\
\hline
\end{tabular}

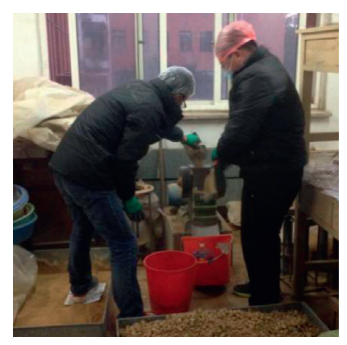

(a)

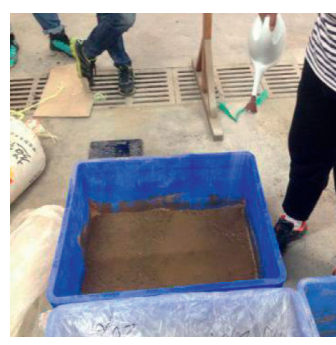

(b)

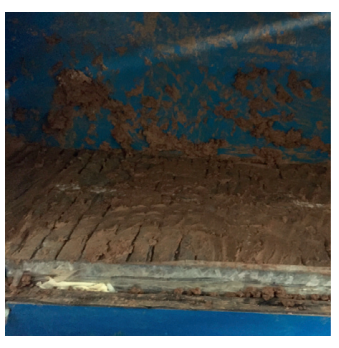

(c)

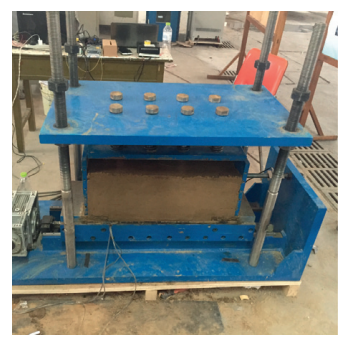

(d)

FIGURE 6: Test preparation. (a) Soil sample grinding. (b) Soil sample preparation. (c) Concrete slab production. (d) Installation.

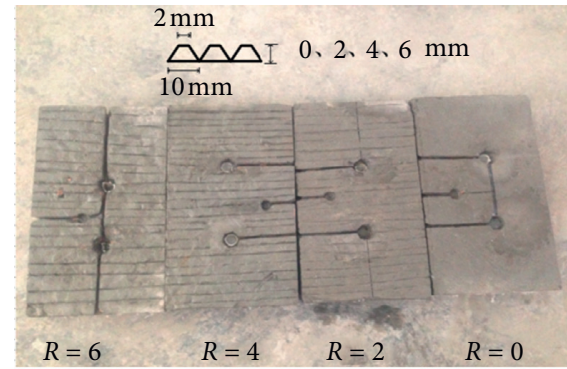

FIgURE 7: Concrete panels of different roughness.

4.2. Influence of Roughness on Interface Shear Failure Displacement. According to the test results, the displacement change curve of shear failure at pile-soil interface under different roughness can be drawn, as shown in Figure 13.



Figure 8: Test device. 


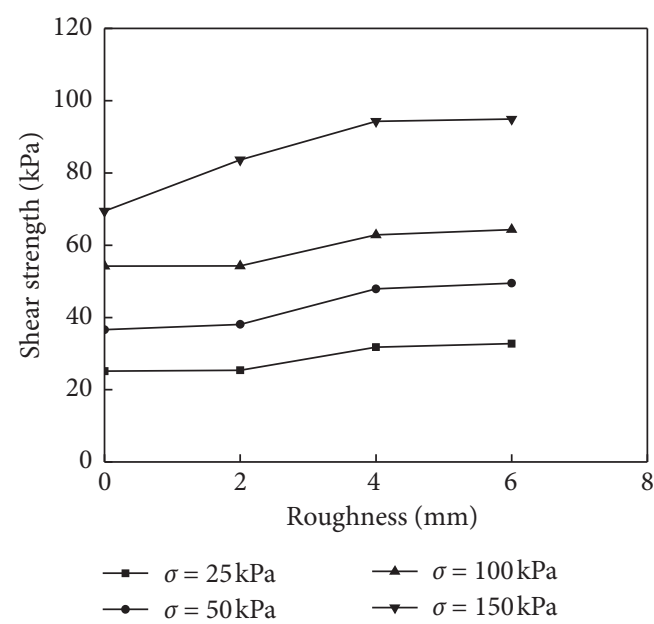

FIgURE 9: Relationship between shear strength of interface and roughness.

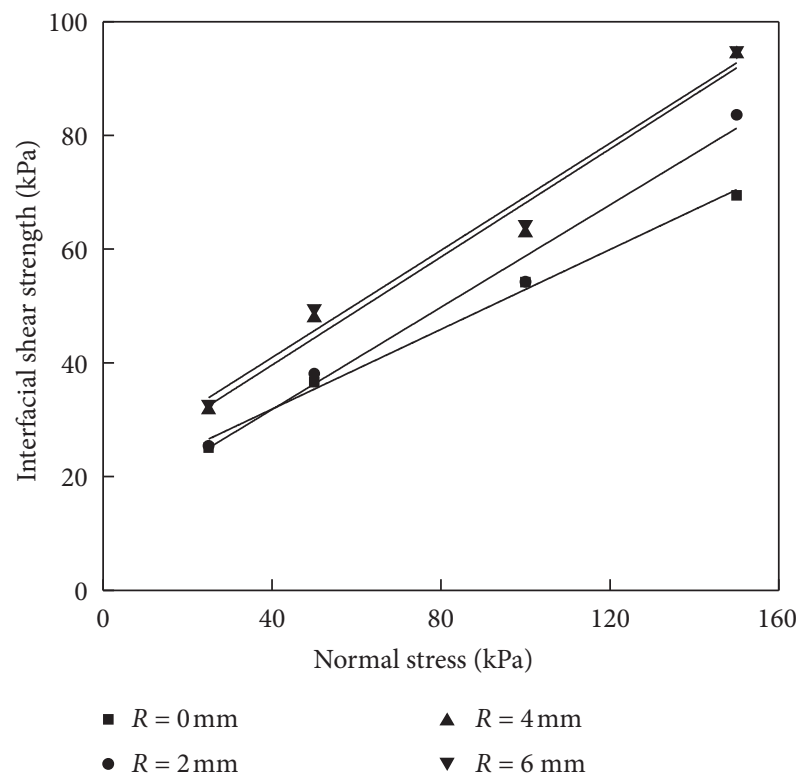

FIGURE 10: Relationship between shear strength of interface and normal stress.

As can be seen from Figure 13, when the normal stress was constant, the interface shear failure displacement increased with the increase of roughness. When the normal stress was $150 \mathrm{kPa}$, with the roughness increasing from $0 \mathrm{~mm}$ to $6 \mathrm{~mm}$, the shear failure displacement increased from $18 \mathrm{~mm}$ to $28 \mathrm{~mm}$, with an increase of $55.5 \%$, indicating that the roughness had a significant impact on the shear failure displacement at the silty clay-concrete interface.

\subsection{Influence of Roughness on Interface Shear Stiffness.} Shear stiffness of solid structures is usually expressed by shear modulus, which cannot be obtained directly in direct shear tests. The experimental results show that the interface shear stress and shear displacement curve increase linearly at

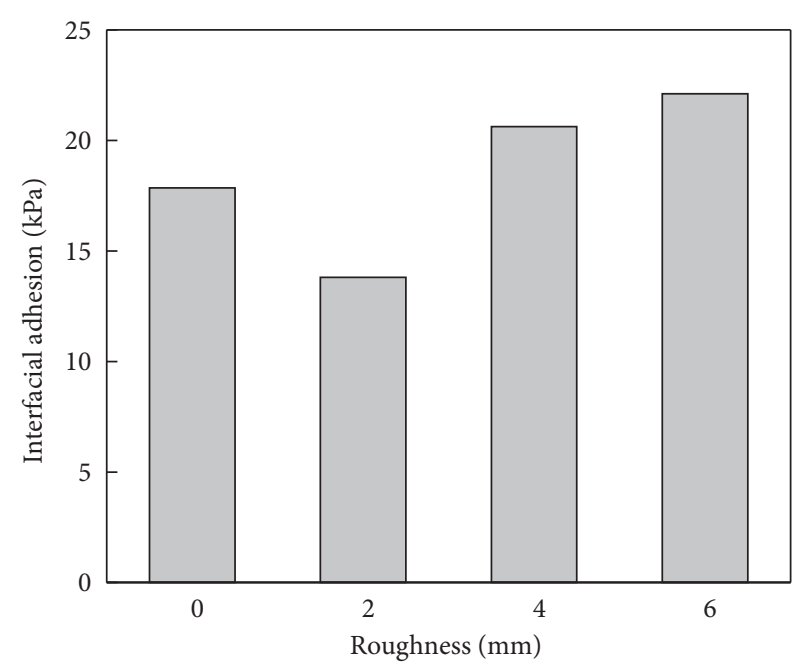

FIGURE 11: Relationship between interface cohesion and roughness.

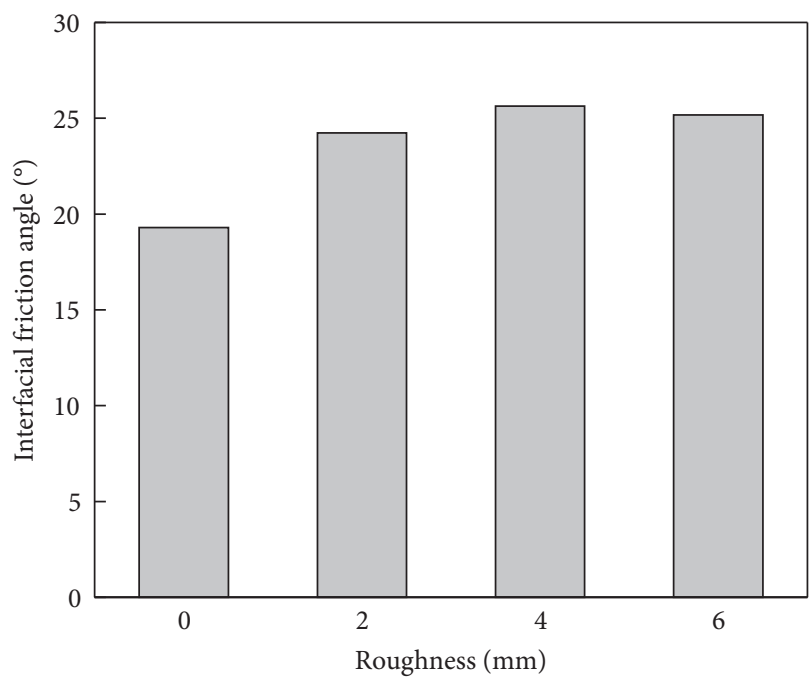

Figure 12: Relationship between interface friction angle and roughness.

the initial stage of loading, and the higher the slope is, the greater the interface shear stiffness will be. The slope of the straight line segment is used to represent the equivalent shear modulus of the pile-soil interface [31], and the calculation formula is

$$
G_{\mathrm{eq}}=\frac{\tau_{\mathrm{e}}}{u_{\mathrm{e}}}
$$

where $\tau_{\mathrm{e}}$ is linear elastic limit for interface shear stress, $\mathrm{kPa}$; $u_{\mathrm{e}}$ is the elastic limit shear displacement of interface line, $\mathrm{mm}$; and $G_{\mathrm{eq}}$ is the equivalent shear modulus at the pile-soil interface, $\mathrm{kPa} / \mathrm{mm}$.

The relationship between the interface equivalent shear modulus and roughness is shown in Figure 14. As can be seen from Figure 14, when the normal stress was the same, the greater the roughness, the greater the equivalent shear modulus of the interface. When $\sigma=100 \mathrm{kPa}$, with the roughness increasing from $2 \mathrm{~mm}$ to $4 \mathrm{~mm}, G_{\text {eq }}$ increased 


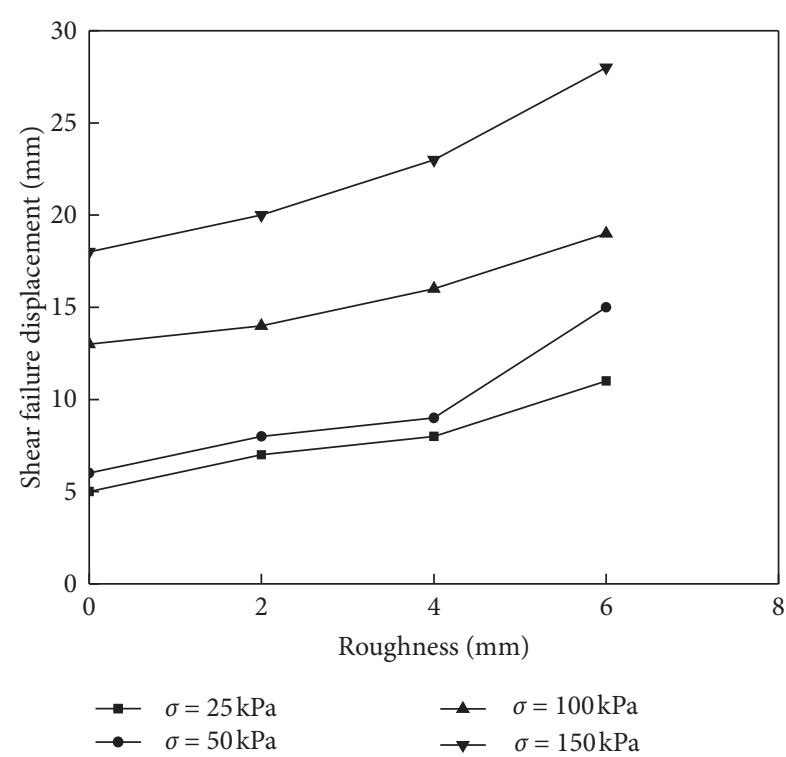

FIGURE 13: Relationship between interface shear failure displacement and roughness.

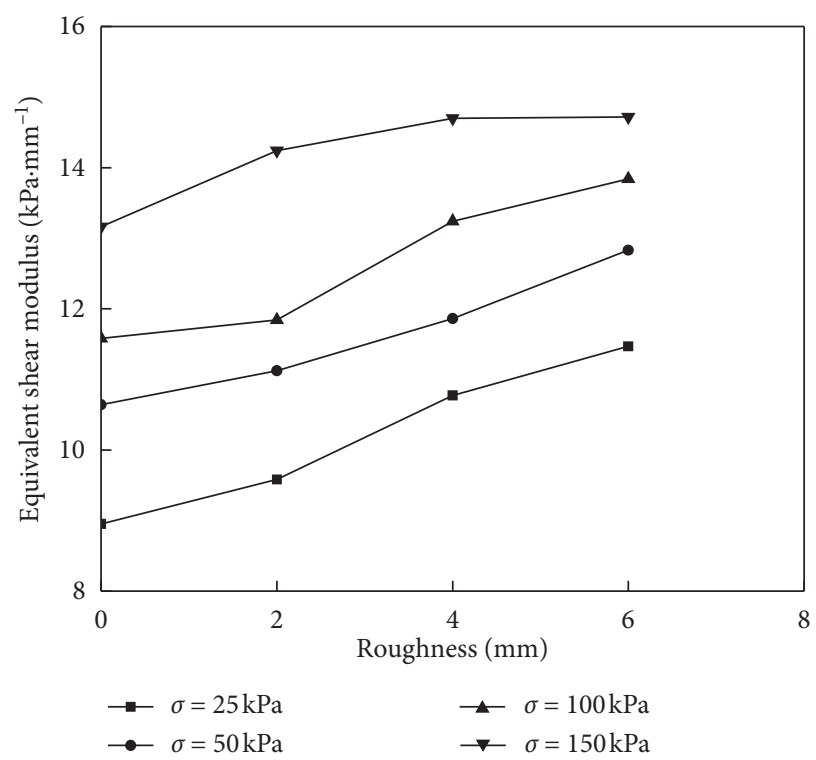

FIgURE 14: Relationship between equivalent shear modulus and roughness.

from $11.84 \mathrm{kPa} / \mathrm{mm}$ to $13.74 \mathrm{kPa} / \mathrm{mm}$, increasing by a large amount to $1.9 \mathrm{kPa} / \mathrm{mm}$ and increasing by $16.0 \%$. With the increase of roughness, the equivalent shear modulus of the interface increased gradually, and the increase was more than $15 \%$. The increase of roughness had a significant optimization effect on the improvement of the shear stiffness of the silty clay-concrete interface.

\section{Discussion}

The factors influencing the shear properties of silty clayconcrete interface include internal and external factors. External factors mainly include temperature, stress state, etc.
The internal factors mainly include the composition, state and structure of soil, mechanical properties of pile contact surface, etc. [32] Under the experimental conditions to study the influence of roughness, when the normal stress of the interface is constant and the moisture content is constant, the roughness of the pile contact surface is the main factor that affects the shear characteristics of the interface between silty clay and concrete. Interface shear strength is composed of adhesion and friction resistance caused by interface slip. The frictional resistance is proportional to the friction angle. Cohesion is the macroscopic embodiment of cementation, occlusion, and water film connection between soil particles and usually plays a major role in the adhesion of soil particles in fine soil. The soil sample in this experiment is clay soil, which has a certain cohesion, which usually accounts for a large proportion of the shear strength. Under different roughness conditions, the shear strength of the interface is $25.12 \sim 94.91 \mathrm{kPa}$, and the interface adhesion is $17.85 \sim 22.11 \mathrm{kPa}$. It can be seen that when the roughness is small, the proportion of the interface adhesion is $71.1 \%$. With the increase of roughness, the proportion gradually decreased to $23.3 \%$. The proportion of frictional resistance increases gradually; that is, the influence of friction angle on shear strength increases gradually with the increase of roughness. Cohesion is the macroscopic manifestation of cementation, bite, and water film connection among soil particles and usually plays a major role in the adhesion of soil particles in fine soil. When the roughness is small, the contact area of the pile-soil interface is large, and the adhesion generated is large, which has a great influence on the shear strength. With the increase of roughness, the contact area of pile and soil gradually decreases, the proportion of frictional resistance gradually increases, and the influence of shear strength gradually increases. For the experiment in this paper, it can be preliminarily judged that the critical roughness is $2 \mathrm{~mm}$. When the roughness is less than $2 \mathrm{~mm}$, the interface adhesion takes a larger proportion in the shear strength with the increase of roughness. With the increase of roughness, the proportion of frictional resistance gradually exceeds that of interface adhesion and becomes the main component of shear strength.

The interfacial frictional resistance is caused by the occlusal friction between the soil particles and the sliding friction between the soil particles and the surface of the concrete block. The effect of the increase of roughness on the frictional resistance of the interface mainly reflects that the increase of roughness makes the mutual friction between the soil near the interface and the interface increase, which significantly increases the frictional resistance caused by the shear slip of the interface, and the frictional resistance is proportional to the friction angle. In addition, the frictional resistance also plays a main role in the shear strength; compared with cohesion effect, the effect of friction on the clay-concrete structure plays a main role in the interface; therefore, regarding the interface friction resistance, the greater the interface shear deformation, the more difficult it is to happen, which increases with roughness, interface friction resistance increases, for the clay-concrete structure stability enhancement interface, and the interface shear 
stiffness increases, when the damage deformation of shear slip increases.

The test results in this paper are consistent with the research results of [33]. In this paper, the numerical value of interface pressure is obtained by using silicon piezoresistive pressure sensor, which is more accurate than previous methods. By simulating the stress at the interface of pile and soil, the stress mechanism of precast piles is studied.

\section{Conclusion}

(1) The silicon piezoresistive sensor can well meet the testing requirements of the shear characteristics of silty clay-concrete interface and clearly reflect the change law of the shear strength with the roughness.

(2) The roughness has an important effect on the shear strength, shear stiffness, and shear failure displacement of the silty clay-concrete interface.

(3) The effect of roughness on interface shear strength and friction angle is more significant than that of adhesion. When the normal stress is the same, with the increase of roughness, the shear strength and friction angle of the silty clay-concrete interface increase significantly, by more than $30 \%$. When the roughness does not reach the critical value, the proportion of interface adhesion is relatively high; when the roughness exceeds the critical value, the proportion of interface adhesion decreases rapidly, and friction resistance becomes the main component of shear strength.

\section{Data Availability}

The experimental data used to support the findings of this study will be made available upon request.

\section{Conflicts of Interest}

The authors declare that there are no conflicts of interest regarding the publication of this paper.

\section{Acknowledgments}

This work was supported by the National Natural Science Foundation of China (51708316, 51778312), the China Postdoctoral Science Foundation Funding (2018M632641), and the Shandong Provincial Postdoctoral Innovation Program of China (201903043).

\section{References}

[1] M. Y. Zhang, X. Y. Bai, Q. Gao et al., "Experimental study on interfacial bearing mechanism of piles in cohesive soil," Rock and Soil Mechanics, vol. 38, no. 8, pp. 2167-2174, 2017.

[2] B. Yuan, M. Sun, L. Xiong, Q. Luo, S. P. Pradhan, and H. Li, "Investigation of 3D deformation of transparent soil around a laterally loaded pile based on a hydraulic gradient model test," Journal of Building Engineering, vol. 28, no. 3, p. 101024, 2020.

[3] B. X. Yuan, M. Sun, Y. X. Wang et al., "Full 3D displacement measuring system for 3D displacement field of soil around a laterally loaded pile in transparent soil," International Journal of Geomechanics, vol. 19, no. 5, Article ID 04019028, 2019.

[4] A. Mirzaghorbanali, J. Nemcik, and N. Aziz, "Effects of shear rate on cyclic loading shear behaviour of rock joints under constant normal stiffness conditions," Rock Mechanics and Rock Engineering, vol. 47, no. 5, pp. 1931-1938, 2014.

[5] S. Xiao, M. T. Suleiman, R. Elzeiny et al., "Soil-concrete interface properties subjected to temperature changes and cycles using direct shear tests," Geotechnical Frontiers, vol. 2017, pp. 175-183, 2017.

[6] M. A. Hossain and J. H. Yin, "Behavior of a pressuregrouted soil-cement interface in direct shear tests," International Journal of Geomechanics, vol. 14, no. 1, pp. 101-109, 2013.

[7] T. D. O'Rourke, S. J. Druschel, and A. N. Netravali, "Shear strength characteristics of sand-polymer interfaces," Journal of Geotechnical Engineering, vol. 116, no. 3, pp. 451-469, 1990.

[8] P. Basu, M. Prezzi, R. Salgado et al., "Shaft resistance and setup factors for piles jacked in clay," Journal of Geotechnical and Geoenvironmental Engineering, vol. 140, no. 3, Article ID 04013026, 2013.

[9] H.-1. Kou, J. Chu, W. Guo, and M.-y. Zhang, "Field study of residual forces developed in pre-stressed high-strength concrete (PHC) pipe piles," Canadian Geotechnical Journal, vol. 53, no. 4, p. 1, 2015.

[10] M. Elkasabgy and M. H. El Naggar, "Axial compressive response of large-capacity helical and driven steel piles in cohesive soil," Canadian Geotechnical Journal, vol. 52, no. 2, pp. 224-243, 2014.

[11] M. Y. Zhang and A. F. Deng, "Experimental study on pile-soil sliding friction," Rock and Soil Mechanics, vol. 23, no. 2, pp. 246-249, 2002.

[12] H. Cheng, X. B. Chen, J. S. Zhang et al., "Experimental study on residual strength characteristics of contact surface of red clay-concrete structure," Journal of Central South University (Natural Science), vol. 48, no. 9, pp. 2458-2464, 2017.

[13] Y. Q. Hu, L. S. Tang, and Z. Y. Li, "Research on sliding friction mechanism of static pressure pile-soil interface," Rock and Soil Mechanics, vol. 36, no. 5, pp. 1288-1294, 2015.

[14] Y. L. Yang, J. G. Zhu, T. Yu et al., "Experimental study of mechanical behaviour of soil-structure interface by ring shear test," Rock and Soil Mechanics, vol. 30, no. 11, pp. 3256-3260, 2009.

[15] K. Peng, J. G. Zhu, D. Zhang, and X. Wu, "Study of mechanical behaviors of interface between coarse-grained soil and concrete by simple shear test," Chinese Journal of Rock Mechanics and Engineering, vol. 29, no. 9, pp. 1893-1900, 2010.

[16] J. W. Liu, M. Y. Zhang, F. Yu et al., "Experimental study on shear fatigue degradation at the interface between soil and PHC pipe piles," Chinese Journal of Geotechnical Engineering, vol. 35, no. s2, pp. 1037-1040, 2013.

[17] Y. Zhou, Z. B. Peng, Q. Yin et al., "Shear properties of SLATE sandy soil-concrete interface," Journal of Central South University (Natural Science Edition), vol. 50, no. 9, pp. 2233-2241, 2019.

[18] C. Xu and F. X. Meng, "Effects of shear rate and material characteristics on shear strength at the rib-soil interface," Rock and Soil Mechanics, vol. 31, no. 10, pp. 3101-3106, 2010.

[19] B. H. Song, W. W. Chen, W. J. Wu et al., "Experimental study on soil moisture content of suoertou landslide," Rock and Soil Mechanics, vol. 33, no. s2, pp. 77-84, 2012. 
[20] X. Y. Jiang, Application Research of MAX1457-Based Silicon Piezoresistive Sensor Can Only Compensate and Calibrate the System, Suzhou University, Suzhou, China, 2006.

[21] M. Hu, J. Z. Ma, J. Zou et al., "Application of micromachining technology in microsensors," Piezoelectricity and AcoustoOptics, vol. 24, no. 4, pp. 268-302, 2002.

[22] C. H. Du, C. D. He, X. Y. Ge et al., "Optimal design of MEMS piezoresistive acceleration sensor," Piezoelectricity and Acousto-Optics, vol. 34, no. 6, pp. 848-852, 2012.

[23] N. Zhang, H. Tang, Q. Liang et al., "Development of low temperature meteorological piezoresistive sensor," Sensors and Microsystems, vol. 34, no. 8, pp. 119-120, 2015.

[24] X. B. Lu, Research on Piezoresistive Properties of Polycrystalline Silicon Nano-Films and Their Application in Pressure Sensors, Harbin Institute of Technology, Harbin, China, 2010.

[25] K. J. Wan, C. D. He, D. Q. Lian et al., "Design and optimization of MEMS piezoresistive ultrasonic sensors," Piezoelectricity and Acousto-Optics, vol. 34, no. 5, pp. 728-731, 2012.

[26] Y. H. Wang, M. Y. Zhang, J. W. Liu et al., "Development and application of a large-scale direct shear test device for pile-soil interface," Chinese Journal of Rock Mechanics and Engineering, vol. 37, no. s1, pp. 3714-3721, 2018.

[27] The Ministry of Water Resources of the People's Republic of China, GB/T50123-2019 Standard for Soil Test Method, China Planning Press, Beijing, China, 2019.

[28] The National Standards Compilation Group of People's Republic of China, JGJ94 - 2008 Technical Code for Building Pile Foundations, China Architecture and Building Press, Beijing, China, 2018.

[29] A. D'Andrea, C. Tozzo, A. Boschetto, and L. Bottini, "Interface roughness parameters and shear strength," Modern Applied Science, vol. 7, no. 10, p. 1, 2013.

[30] K. Hayashi, T. Inadome, H. Tsumura, Y. Nakashima, and Y. Sugioka, "Effect of surface roughness of hydroxyapatitecoated titanium on the bone-implant interface shear strength," Biomaterials, vol. 15, no. 14, pp. 1187-1191, 1994.

[31] J.-P. Yang, W.-Z. Chen, Y.-h. Dai, and H.-D. Yu, "Numerical determination of elastic compliance tensor of fractured rock masses by finite element modeling," International Journal of Rock Mechanics and Mining Sciences, vol. 70, no. 70, pp. 474-482, 2014.

[32] J. H. Chen, J. S. Zhang, and J. Li, "Influence of interface roughness on mechanical properties of red clayconcrete interface," Journal of Central South University (Science and Technology), vol. 47, no. 5, pp. 1682-1688, 2016.

[33] H. Harris and V. Sarfarazi, "The effect of micro pore on the characteristics of crack tip plastic zone in concrete," Computers \& Concrete, vol. 17, no. 1, pp. 107-127, 2016. 